\title{
«Por uma Informação ao serviço do processo revolucionário»: o «caso dos 24» do Diário de Notícias na revolução portuguesa
}

\section{Resumo}

Este artigo analisa o caso dos jornalistas saneados do jornal Diário de Notícias, no verão de 1975. Iniciado em agosto desse ano, o chamado «caso dos 24" coincide com um dos momentos mais "quentes" do período revolucionário português, em que se intensificam as tentativas de controlo político-ideológico dos meios de comunicação social. Verificamos, entre outras coisas, que, efetivamente, este caso não foi apenas um problema laboral, mas antes um problema que se inseriu num contexto mais vasto: uma luta política que marcou o país entre 1974 e 1975.

Palavras-chave: Diário de Notícias. Revolução.

Saneamentos Políticos. Portugal.

\section{Pedro Marques Gomes}

Doutor em História Contemporânea pela Faculdade de Ciências Sociais e Humanas da Universidade Nova de Lisboa e investigador integrado do Instituto de História Contemporânea da mesma universidade. Professor na Escola Superior de Comunicação Social do Instituto Politécnico de Lisboa. Lisboa - PORTUGAL pedromarquesgomes@gmail.com orcid.org/0000-0002-3189-3388

\section{Para citar este artigo:}

GOMES, Pedro Marques. «Por uma Informação ao serviço do processo revolucionário»: o "caso dos 24" do Diário de Notícias na revolução portuguesa. Tempo e Argumento, Florianópolis, v. 11, n. 28, p. 261 - 292, set./dez. 2019.

DOI: $10.5965 / 2175180311282019261$

http://dx.doi.org/10.5965/2175180311282019261

\footnotetext{
* Nesse texto optou-se por manter a grafia da língua nativa (Língua Portuguesa - Portugal).
} 


\title{
«For an information at the service of the revolutionary \\ process»: the «24 case» of the \\ Diário de Notícias in the \\ Portuguese revolution
}

\begin{abstract}
The main aim of this article is to examine the purges carried out in the Diário de Notícias, in the summer of 1975. Started in August of that year, the so called « 24 case» takes place in one of the hottest moments of the Portuguese revolution, in which the attempts of political and ideological control of media increase. We observe, among other things, that the " 24 case» falls within a broader context than just of a labor problem: the political struggle that sweeps the country in the years of 19741975.
\end{abstract}

Keywords: Diário de Notícias. Revolution. Political Purges. Portugal.

\section{Introdução}

A 25 de Abril de 1974 o Movimento das Forças Armadas (MFA) derruba a ditadura que vigorava em Portugal há mais de quatro décadas. O país vai então viver um processo revolucionário, feito de avanços e recuos político-militares, com as forças em presença a digladiarem-se devido aos diferentes projetos políticos que defendiam para o futuro do país. Estava em causa a definição do tipo de regime a implementar em Portugal.

O setor da Informação foi particularmente afetado pela conjuntura revolucionária, envolvendo-se e tomando partido no curso dos acontecimentos. Abolida a censura, os jornais e os jornalistas foram, efetivamente, atores políticos relevantes deste período, no sentido em que influenciam outros atores (governo, partidos políticos, grupos de 
interesse, movimentos sociais, etc.), na terminologia de Héctor Borrat (1989: 67). Alguns dos episódios mais emblemáticos do chamado Processo Revolucionário em Curso (PREC) envolveram órgãos de comunicação social, sendo disso exemplos os casos Renascença (RIBEIRO, 2002; SANTOS, 2005), República (MESQUITA, 1987; REBELO, 2018) e do Diário de Notícias (GOMES, 2014), todos eles com contornos que vão além da questão da liberdade de expressão ou de imprensa.

O propósito deste artigo é o de analisar este último episódio, que ocorre em pleno «verão quente» de 1975, o momento mais radicalizado e polarizado da revolução portuguesa. Através de bibliografia diversificada, documentação, materiais de imprensa e da recolha de testemunhos de alguns dos seus protagonistas, pretendemos analisar o processo que originou o saneamento de parte dos jornalistas do Diário de Notícias (DN), à época o jornal diário com maior tiragem no país, inserindo-o no contexto político e mediático da época e apresentando os seus principais desenvolvimentos.

\section{A imprensa, os saneamentos e o processo revolucionário}

"O desmantelamento do Estado opressivo tornou-se a primeira das reivindicações da sociedade portuguesa mal a liberdade lhe permitiu expressá-la" (LOFF, 2016). Presidente da República, Presidente do Conselho, membros do governo, entre outros, são, de imediato, saneados e a polícia política dissolvida (PIMENTEL, 2017). Os serviços de censura são também encerrados (e assaltados) no imediato pós 25 de Abril.

Entre as várias preocupações que dominam o período encontrava-se a necessidade de afastamento dos indivíduos acusados de conivência e colaboracionismo com o regime. Em instituições estatais, empresas e fábricas as revoltas e protestos de trabalhadores contra esses elementos foram, a partir de então, frequentes. Traduziramse, em grande medida, em processos de saneamento que visavam "depurar e reformar as instituições de maneira a proporcionar a instauração da ordem democrática" (REZOLA, 2013, p. 177-178). Processos que estiveram longe de ser pacíficos, as primeiras purgas, após as das cúpulas do Estado, “ocorrem espontaneamente em várias empresas e as exigências de saneamentos fizeram parte das palavras de ordem das primeiras greves" (PINTO, 2001, p. 364). 
No caso da comunicação social, tendo sido uma das áreas particularmente afetadas "pela censura em conjugação com administradores e/ou direções de redação afetos ao regime ditatorial" mais facilmente se compreende que "as primeiras reivindicações da classe jornalística tenham sido no sentido de afastar os responsáveis por essas formas de opressão" (LIMA, 2008, p. 184). É possível detetar uma tendência em termos de "agentes de saneamento": "eram principalmente jornalistas e tipógrafos ligados ao Partido Comunista e às organizações de extrema-esquerda, cuja preponderância continuou durante o chamado "período revolucionário»" (PINTO, 2001, p. 371).

Em grande parte dos jornais, diretores e administradores acabam por ser afastados. Como principal consequência das substituições nas hierarquias superiores das empresas jornalísticas há que destacar uma "significativa viragem nos planos editoriais e de conteúdos, os quais passam a apoiar de forma decisiva e explicita o novo poder político" (SILVEIRA, 2011, p. 129). Ou seja, numa primeira fase, a imprensa passa a estar com o MFA.

Paralelamente, com mais ou menos semelhanças, as transformações nos jornais vão ocorrendo, tendo eco nas páginas dos respetivos (e noutros) periódicos. De uma maneira geral, vamos assistir à aceitação das reivindicações dos trabalhadores por parte das administrações, embora, em alguns casos, as negociações se tenham arrastado para além do desejável, originando greves, manifestações e, claro, muitos plenários de trabalhadores. São eleitas Comissões de Trabalhadores, que passam a ter um poder elevado no interior das empresas de media. Relativamente aos conteúdos dos jornais, verificamos, desde logo, que nem sempre era clara a distinção entre artigos informativos e opinativos. Num texto apresentado como uma notícia era comum surgirem comentários que colocavam em evidência a posição do jornalista sobre o assunto tratado, sendo também frequente o recurso à adjetivação. Emerge a ideia de um “jornalismo revolucionário", no sentido em que se imiscui nos acontecimentos e não deixa de tomar posição.

Ao tentar sintetizar o panorama dos media portugueses entre 1974 e 1975, Mário Mesquita apresenta três tendências dominantes que percorreram o período, referindo-se 
aos "herdeiros do antigo regime, que procuravam retardar o pleno desmantelamento dos mecanismos censórios", aos "defensores de teses revolucionárias e vanguardistas" que eram favoráveis "à adoção de formas de censura a posteriori" e aos "partidários de conceções pluralistas do sistema de comunicação social”, defendendo o fim da repressão administrativa (MESQUITA, 1994, p. 360-361). De facto, o período que se seguiu à revolução de 25 de Abril de 1974 foi marcado, no que diz respeito ao setor da Informação, por uma luta intensa pelo controlo dos órgãos de comunicação social e, sobretudo, pelo controlo da sua orientação editorial, o que, naturalmente, deu origem a múltiplos conflitos, envolvendo sobretudo os trabalhadores do sector e os centros de poder político-militares'.

No que diz respeito ao jornal que aqui analisamos, o Diário de Notícias, há a salientar, desde logo, que este era considerado o órgão "oficioso" do Estado Novo. Fora dirigido por Augusto de Castro, destacada figura do regime, tendo sido também no DN publicadas as célebres entrevistas feitas por António Ferro a Oliveira Salazar. Fernando Fragoso, diretor do periódico em 1974, enfrentará uma forte ação contra a sua permanência no cargo depois de derrubada a ditadura. No interior da redação vivia-se um mistro de emoções, como recorda o jornalista José António Santos: “Não escondo que nalguns rostos vi surpresa e desânimo, porque havia camaradas nossos de profissão que eram alinhados com o Estado Novo e perceberam que o sonho tinha ruído. Mas o grande sentimento da redação é de júbilo e de contentamento" (Entrevista cedida por José António Santos ao autor, Lisboa, 2012).

Após mais de um mês de múltiplas tentativas, historiadas num relatório de Saneamento Interno publicado no próprio jornal, em junho os trabalhadores conseguem finalmente afastar aqueles que consideravam ser os "porta-estandartes do fascismo". Abandonam então as suas funções Fernando Fragoso (diretor), João Coito (chefe de redação), Dutra Faria (fundista), Pessoa Araújo (diretor técnico), Mário Costa (diretor administrativo), Pedro Pitta (consultor jurídico) e Sena Lino (clínico domiciliário). Os administradores da Empresa Nacional de Publicidade (detentora do jornal) - Ulisses Cortez (ex-ministro de Salazar), Esteves da Fonseca (ex-secretário de Estado da Indústria)

\footnotetext{
${ }^{1}$ Sobre os principais conflitos e episódios que ocorrem na imprensa, cf. Gomes, 2018.
} 
e Vitória Pires (ex-secretário de Estado de Marcello Caetano) - são também destituídos, à exceção de João Pires Dinis, representante dos acionistas privados, que assume interinamente a direção enquanto novas medidas de saneamento estavam na forja.

A 25 de junho é nomeada uma nova direção, composta por José Ribeiro dos Santos, antigo chefe de redação do República e do Diário de Lisboa e diretor do serviço de ciência da Fundação Calouste Gulbenkian, e por José Carlos de Vasconcelos, seu adjunto, que também havia passado pelo Diário de Lisboa. O DN passa assim a contar com uma direção próxima do Partido Socialista (o diretor era mesmo um dos seus fundadores) e da ala moderada do MFA. Novos jornalistas ingressam na redação, numa estratégia da direção de imprimir uma nova dinâmica no jornal.

Refira-se que depois da fase inicial de "saneamentos", estes não terminam, sendo que, em alguns casos, como no DN, ganham proporções ainda maiores. De acordo com António Costa Pinto, “em termos gerais, o processo de saneamento (purgas políticas) não se regeu por estratégias claras nem por nenhum padrão coerente. Diferiu muito de sector para setor". Se, em 1974, os "saneamentos baseavam-se num conceito estrito de colaboracionismo", em 1975 "vários tipos de atitudes autoritárias de industriais e empresários eram considerados como associados ao antigo regime" (PINTO, 2006, p. 45).

Efetivamente, o que se vai verificar é que, longe de terminarem nos meses seguintes ao derrube da ditadura, os processos de saneamento ganham outros - e diversos - contornos. Fugindo, “muitas vezes, ao controlo das autoridades, num processo cheio de particularidades e tensões, reflexo da complexidade da revolução portuguesa" (REZOLA, 2013, p. 179), as purgas vão sendo concretizadas de diferentes formas. Ou seja, a par de saneamentos levados a cabo de acordo com a legislação em vigor, são efetuados "saneamentos selvagens" (à margem das leis entretanto produzidas). As Comissões de Trabalhadores tiveram, neste contexto, particular responsabilidade, uma vez que os pedidos de afastamento eram feitos através dessas Comissões “onde o PCP [Partido Comunista Português] tinha de partilhar o controlo com os outros partidos da extremaesquerda" (PINTO, 2006, p. 44). Vejamos agora o que acontece no DN, já em 1975. 


\section{O Diário de Notícias e o «verão quente» de 1975}

Cerca de um ano após a revolução, o contexto político-militar vivido é de duros confrontos. O pós-11 de Março de $1975^{2}$ é caracterizado por ser um período de crescente hegemonia dos setores afetos ao primeiro-ministro Vasco Gonçalves e ao PCP. Por outro lado, acontecimentos que vão ocorrer já em julho e agosto, como a queda do IV governo provisório, a constituição do frágil V governo provisório e a "epidemia de planos" surgidos são os que maiores consequências produzem em termos da correlação das forças em presença (REZOLA, 2006). No verão de 1975, o Partido Socialista (PS) assumia uma importância que até então não havia atingido. À legitimidade eleitoral adquirida com o resultado das eleições para a Assembleia Constituinte (em abril) juntava-se o novo papel no processo revolucionário rumo ao socialismo. O PS sentia-se, assim, "legitimado para desempenhar um papel determinante na defesa de uma via democrático-pluralista e erigir-se em obstáculo à hegemonização da revolução por uma aliança entre o MFA e o Partido Comunista" (REIS, 1993, p. 44).

De facto, após a tentativa de golpe dirigida pelo general Spínola, vive-se um novo momento político. O rumo da revolução sofre uma mudança acentuada, em grande medida fruto das várias iniciativas do recém-criado Conselho da Revolução (CR), sendo disso exemplo a nacionalização da Banca. Esta acabaria por originar alterações relevantes na imprensa nacional, pois vários jornais pertenciam a bancos e passaram, assim, para o setor público, assistindo-se a partir daí a uma intensificação das lutas pelo controlo da imprensa:

É sobretudo na primeira fase do período entre o 11 de Março e o 25 de Novembro que se acentua a influência e a manipulação partidária na imprensa, designadamente por elementos afetos ao Partido Comunista Português e a organizações de extrema-esquerda.

A atuação de grupos ou de comissões de trabalhadores foi o principal instrumento daquela influência ou manipulação partidária, agindo no mesmo sentido o alargamento drástico da intervenção estatal na maior parte da imprensa diária, na medida em que o próprio Estado também era influenciado pelas teses de forças comunistas.

\footnotetext{
${ }^{2}$ A 11 de Março de 1975 houve uma tentativa falhada de golpe de Estado, desencadeada pelo ex-Presidente da República, general António de Spínola. Sobre o pós 11 de Março, cf, por exemplo, Rezola, 2006.
} 
A informação estatizada (e alguma informação privada) caracterizou-se, nessa altura, por um tom monolítico e, em alguns casos, propagandístico (...) (RELATÓRIO DO CONSELHO DE IMPRENSA, 1979, p. 43).

A este respeito, o exemplo do Diário de Notícias, que já pertencia ao Estado há vários anos 3 , é particularmente elucidativo, como nos mostram os investigadores Seaton e Pimlott:

A situação mais dramática (mas, também, a mais previsível) foi a do Diário de Notícias, o matutino de Lisboa de maior circulação, que tinha sempre seguido as posições do antigo regime. Em 1974, o Diário de Notícias transcrevia fielmente os procedimentos do congresso da União Nacional Portuguesa (o partido do governo). Em abril de 1975, reportava com a mesma calma e tom referencial os encontros da central sindical comunista, Intersindical. Os mesmos jornalistas escreviam da mesma maneira, com a mesma aceitação da autoridade política prevalecente" (SEATON; PIMLOTT, 1983, p. 102).

Afastada a direção Ribeiro dos Santos/José Carlos Vasconcelos ${ }^{4}$, desde o início de abril o Diário de Notícias era dirigido por Luís de Barros (diretor) e José Saramago (diretoradjunto), ambas figuras próximas do Partido Comunista Português, embora o primeiro só viesse a filiar-se mais tarde. Zita Seabra, então militante do PCP, clarifica a estratégia do partido: "uma das condições para a vitória da revolução era o controlo dos órgãos de comunicação social” (SEABRA, 2007, p. 288). Outro militante do PCP, José Jorge Letria, reforça esta ideia. Até então jornalista do República, ingressa na redação do DN na mesma altura que a nova direção:

O partido deu-nos uma orientação para sairmos dali [do República] e irmos reforçar posições que precisavam de ser reforçadas. Houve jornalistas que foram para o Diário de Notícias, outros foram para a ANOP, que também precisava de ser reforçada, e um ou dois foram para a RTP. Portanto, eu desde que tive essa orientação tive uma orientação também para ir falar com o Luís de Barros (Entrevista concedida por José Jorge Letria ao autor, Lisboa, 2011).

\footnotetext{
${ }^{3}$ Na prática, o jornal pertencia ao Estado, uma vez que a Caixa Geral de Depósitos era detentora da empresa “Portugal e Colónias" e esta da Empresa Nacional de Publicidade, proprietária do Diário de Notícias.

${ }^{4}$ Os trabalhadores do DN decidem, em plenário, retirar o apoio ao diretor, após estes publicar um editorial, intitulado "Não", condenando as propostas, alegadamente feitas em Assembleia do MFA, de fuzilamento dos militares implicados no 11 de Março. O diretor demite-se e o seu adjunto solidariza-se e toma atitude idêntica.
} 
Rapidamente o partido passa a ter uma posição preponderante em alguns dos mais importantes órgãos de comunicação social:

O PCP conseguiu aqui igualmente importantes resultados, aproveitando muito bem a confusão criada nas redacções e, quando esta não é suficiente, jogando com o domínio dos sindicatos dos tipógrafos e outros trabalhadores para obter resultados. Basta referir que, ao fim de alguns meses, O PCP é a força dominante nas principais estações de rádio, na RTP e em periódicos tão importantes como o Diário Popular, O Século e o Diário de Notícias (TELO, 2008, p. 58).

Tentando inverter este cenário de hegemonia dos comunistas, nos meses seguintes, O PS irá esforçar-se para afastar O PCP não só do domínio dos media mas também de diversos setores da sociedade portuguesa. No caso concreto do DN, Luís de Barros, diretor do jornal, lembra que na altura "se fazia política em todo o sítio" e, por isso, "os jornais, evidentemente, eram, por excelência, meios para a comunicação política". No entanto, nega taxativamente a ideia de que o Diário de Notícias esteve ao serviço do PCP, dizendo que "o DN tinha o seu Estatuto Editorial e regia-se unicamente por ele" (BARROS apud FIGUEIRA, 2007, p. 198-199). Também o seu adjunto recusa a ideia de que terão sido impostas ideologias político-partidárias aos trabalhadores:

Engana-se, ou engana, e tem interesse na difusão do engano, quem afirmar que impus convicções políticas minhas aos trabalhadores do jornal, ou que me servi deles como abonação de um tipo de esclarecimento e crítica política em que necessariamente nem todos poderiam convergir (SARAMAGO, 1990, p. 192).

Nos discursos de tomada de posse a nova direção do jornal revelou, perante os seus colaboradores, a orientação pretendida para o futuro. Luís de Barros afirmou que o "DN deve acompanhar o exemplo de perseverança e coragem do MFA e tem de estar voltado para a defesa dos interesses do povo português, indo, porventura, à frente do processo revolucionário em curso e utilizando a liberdade de imprensa com vista à conquista de novas liberdades" (O DN..., 1975, p. 1). Na mesma altura, José Saramago pretendia que o DN fosse "um instrumento nas mãos do povo português, para a construção do socialismo" e que quem não estivesse “empenhado neste projeto" seria 
melhor "abandonar o Diário de Notícias" " (O DN..., 1975, p. 1). Tornava-se então pública a linha editorial que o jornal passaria a ter.

O estudo realizado por João Figueira sobre o conteúdo noticioso do DN no Verão de 1975, revela que as promessas feitas pela nova direção aquando da sua tomada de posse foram cumpridas de forma clara. O investigador conclui que "O PCP, o MFA e o general Vasco Gonçalves foram, respetivamente, o partido, a instituição e a figura que mais vezes foram referidos nos títulos do jornal” e essas referências foram feitas "sempre de forma elogiosa e com maior destaque e acesso ao espaço do jornal que os opositores ao conteúdo proposicional apresentado pelo jornal." O jornal adotava, assim, "como sua toda a ação política de Vasco Gonçalves e das forças identificadas com ele e com o PCP”, sendo que, a nível jornalístico, tal "materializou-se, quase sempre, através de uma diabolização dos seus adversários e da atribuição do uso indiscriminado da palavra aos que apoiava" (FIGUEIRA, 2007, p. 135). A juntar a este cenário, também os editoriais da responsabilidade da direção, intitulados Apontamentos, causavam polémica dentro e fora do DN devido às posições políticas neles defendidas.

Paralelamente, em frente às instalações do jornal, verificaram-se manifestações contra o seu conteúdo noticioso, com frases de ordem como "o Diário de Notícias é do Povo não é de Moscovo" e identificando-o como o Pravda (que fora o jornal oficial do Comité Central do Partido Comunista da União Soviética) português, fazendo o jornal eco dessas críticas e apontando o Partido Socialista como principal responsável.

\section{O «documento dos 30» e a suspensão dos jornalistas}

São vários os jornalistas que descrevem o ambiente vivido, nesta altura, no DN como tenso. É o caso da veterana Manuela de Azevedo, que já tinha integrado a redação de publicações como o Diário de Lisboa ou Vida Mundial, dizendo que no DN sofreu "o que nunca tinha sofrido: foi a censura dos Comunistas. Não podia escrever o nome do Mário Soares ou do Francisco Zenha que eles não cortassem" (Entrevista concedida por Manuela de Azevedo ao autor, Lisboa, 2011). Outro jornalista, Mário Contumélias, não tem dúvidas em afirmar que "o Diário de Notícias era, a partir de um dado momento, o jornal 
do $P C$ " e que a censura de que os jornalistas eram vítimas era feita de forma aberta: “Mário Ventura Henriques [Repórter Principal] chegava à redação do Diário de Notícias, tirava a pistola, punha a pistola em cima da mesa e sentava-se a fazer censura" (Entrevista concedida por Mário Contumélias ao autor, Lisboa, 2011).

Apesar de o director do jornal ser Luís de Barros, quem efetivamente "mandava" era José Saramago, refere Mário Zambujal5. No entanto, segundo conta José David Lopes, repórter que se encontrava no jornal desde 1969, quando José Saramago chegou ao DN "não mexeu muito na redação e havia até pessoas de direita que eram enviadas ao Parlamento para cobrir a [Assembleia] Constituinte." Só mais tarde, quando "o clima político começou a ficar muito extremado" e a redação "profundamente dividida", é que se notou "um maior intervencionismo da direção" (O DIRECTOR..., 2010)6. José Jorge Letria tem outra opinião, bem mais polémica, que se prende com o controlo político do periódico: "Eu acho que o verdadeiro diretor do jornal é o Cunhal. Como vem a ser depois de O Diário. Eu acho que a direção política do jornal era feita a partir da António Serpa [sede do PCP]" (Entrevista cedida por José Jorge Letria ao autor, Lisboa, 2011). Relatos controversos sobre a luta política que se vivia na empresa.

A ação dos jornalistas era também condicionada pela Tipografia e pela Comissão de Trabalhadores, que "começa a assumir um poder, porventura, excessivo" e que, de acordo com o director do jornal, "dificilmente se poderia combater" (Entrevista cedida por Luís de Barros ao autor, Lisboa, 2011). Este tipo de conflitos são cruciais para se entender o ambiente vivido entre as paredes do DN, na medida em que envolviam também os jornalistas e o conteúdo dos artigos do jornal. É precisamente isso que João Candeias, tipógrafo e membro da Comissão de Trabalhadores, revela claramente ao dizer que os tipógrafos tentavam impor a sua opinião sobretudo "naquilo que não devia sair" nas páginas do periódico. Tratava-se de uma "classe muito contestatária" e "muito aguerrida", que olhava para os jornalistas com algum distanciamento: "Nós sentíamos

\footnotetext{
${ }^{5}$ Refira-se que Mário Zambujal era director do Mundo Desportivo, também pertencente à ENP.

6 Refira-se que alguns jornalistas foram afastados do jornal no início da atividade da direção Barros/Saramago, sem passarem pela Comissão de Saneamento da ENP, criada em março e composta por elementos de todos os setores da empresa, mas sem registos de propostas de purga. No primeiro, e único, comunicado da Comissão pede-se a colaboração de todos os trabalhadores da empresa no sentido de apresentarem propostas de saneamento, a serem validadas em plenário de trabalhadores. Cf. COMUNICADO N¹, 1975 .
} 
sempre que os jornalistas eram uma classe que era um pouco diferente, era mais elitista" (Entrevista cedida por João Candeias ao autor, Lisboa, 2012). Francisco Máximo, salientando uma das críticas que mais controvérsia vem a causar no verão de 1975 - a existência de censura no jornal - refere:

A manipulação era tanta... A preparação do Diário de Notícias para o PC tomar o poder era tal, o alinhamento era tal, que começou a ser um pouco deplorável a forma como a direção e as chefias apelavam... Era a censura descarada, era a manipulação descarada, era a censura não só no ato, mas também na marcação de serviços. Era condicionar toda a seleção... (Entrevista cedida por Francisco Máximo ao autor, Lisboa, 2011).

Por outro lado, Figueiredo Filipe, responsável pela secção relativa aos temas “Trabalho e Sindicalismo”, explica que, por vezes, os problemas surgiam da necessidade de "emendar a notícia” e não propriamente da prática de censura, recordando um episódio que vivenciou:

Um tipo que foi fazer um serviço no exterior e que, quando chegou ao jornal, fez uma notícia estapafúrdia. O mais importante para ele era uma coisa que não tinha interesse e aquilo que era importante efetivamente estava no fim da notícia, perdido. É lógico que eu inverti as coisas. Não cortei nada, inverti a notícia. Ele foi fazer queixa à direção alegando que tinha havido censura (Entrevista cedida por Figueiredo Filipe ao autor, Lisboa, 2012).

Completamente diferente é a opinião de Acácio Franco. O então repórter fotográfico do $D N$, diz que este jornal era “cada vez mais contestado pelos leitores devido ao sectarismo e falta de objetividade da direção chefiada por Saramago" e relata, anos depois, um episódio que se passou consigo, enquanto desenvolvia trabalho de reportagem no exterior do jornal, em pleno «verão quente» de 1975:

Saio em reportagem para fotografar uma «manif» promovida pelo PC em Belém. O redator escreve que estavam presentes milhares e milhares de pessoas. Os meus bonecos não podiam mostrar o que não havia - e a «manif», fotografada de todos os ângulos possíveis, acabou reduzida à sua verdadeira dimensão, que não condizia absolutamente nada com a grandiosidade da notícia. Resultado: o sr. Mário Ventura Henriques, fiel executor das diretivas do chefe Saramago, chama-me ao seu gabinete onde, em tom exaltadíssimo, me acusa de sabotar a reportagem e ameaça com um processo disciplinar (FLASHES..., 1992, p. 12). 
Bem mais moderado, Fernando Pires, que dividia o seu gabinete com Silva Costa (chefe de redação) e Mário Ventura Henriques, recorda-se deste último questionar o conteúdo das páginas do jornal, causando atritos com o chefe de redação:

Silva Costa saía da sala, por qualquer razão de serviço, e Mário Ventura Henriques levantava-se da sua secretária, vinha olhar a página e questionava a sua elaboração. Isto em manchete, observa ele, mas isto não tem importância nenhuma, isto aqui (o segundo, ou o terceiro títulos), é que deve estar em cima. Eu ouvia, mas não atendia, não dava seguimento. Por vezes, Mário Ventura questionava o próprio Silva Costa sobre a ordem dos títulos da $1^{\mathrm{a}}$ página. Geravam-se discussões (...) (PIRES, 2012, p. 70).

São, portanto, muitos destes fatores que levam alguns desses jornalistas a reunirem-se informalmente para trocarem ideias de como poderiam resolver os problemas que estavam a ocorrer na redação. Decidem-se pela elaboração de um documento onde expuseram as suas posições, divulgando-o, de seguida, pela redação, tendo em vista a obtenção de apoiantes. A reação inicial foi bastante favorável, a julgar pelo testemunho de Rui Tovar, um dos que se empenhou nessa missão:

Houve quem aderisse de imediato e pusesse o seu nome. Houve outros que fizeram questão de primeiro ver quem é que tinha assinado primeiro para ver se valia a pena, se havia alguém credível. Aconteceu isso. Como tínhamos lá o Dr. Manuel Rodrigues, que era uma figura de prestígio e a Manuela de Azevedo, que até era militante do Partido Socialista, isso pesou para alguns, que acharam que havia ali uma seriedade. Porque se fosse só malta de 20 e tal anos podia-se pensar que era uma brincadeira de rapazes e então os mais velhos não iriam aderir (Entrevista cedida por Rui Tovar ao autor, Lisboa, 2011).

A iniciativa saldou-se num sucesso, pois 30 dos pouco mais de 60 jornalistas que integravam a redação subscreveram o documento que virá a ser conhecido como «documento dos 30», numa alusão ao número de jornalistas que o assinou?. No grupo encontravam-se jornalistas de vários quadrantes políticos. Todavia, apesar das diferentes

\footnotetext{
7 Os 30 jornalistas que assinaram o documento foram: Acácio Franco, António Mendes, António Pereira Alves, Aberto Santos, Alda Mafra, Álvaro Gomes, Adelino Alves, Cordeiro Pereira, Francisco Máximo, João Mendes, João Salvado, João Garin, Jorge Soares, Jorge Tavares Rodrigues, José Simões Ilharco, José Sousa Barros, José Valente, José Sampaio, Luís d’Oliveira Nunes, Mário Contumélias, Mateus Boaventura, Manuel Luís Rodrigues, Manuel Pereira Rodrigues, Manuela de Azevedo, Maria Manuela Ferreira, Manuel Andrade Guerra, Raul Nascimento, Rui Tovar, José Estêvão Santos Jorge, Rui Homem.
} 
correntes político-partidárias que caracterizavam os elementos do grupo, Luís d'Oliveira Nunes recusa terminantemente a ideia de que havia partidos políticos por trás da luta dos «30»: "Não havia nenhuma força política, fosse de que natureza fosse, a controlar-nos. Foi um instinto coletivo de reação àquela mordaça" (Entrevista cedida por Luís d'Oliveira Nunes ao autor, Lisboa, 2012). Ainda no que diz respeito à composição do grupo, Manuela de Azevedo recorda que a luta pela defesa do pluralismo informativo foi um dos fatores de união do grupo:

Não estávamos todos alinhados nas mesmas ideologias. Mas havia entre nós um denominador comum que nos unia, essa recusa ao desrespeito pelo pluralismo, esse atropelo à verdade que era em pleno gonçalvismo a Imprensa portuguesa e, muito particularmente o nosso jornal. Para mim e só por mim quero falar - era afrontoso o sectarismo (NÃO DOU..., 1976, p. 2).

A 12 de agosto de 1975 estavam reunidas as 30 assinaturas do «documento dos 30", dividindo-se este em seis pontos fundamentais, onde se expõem as razões do descontentamento dos jornalistas: (1) A “crescente onda de descrédito” sobre o jornal, aferida através das recorrentes "contestações e desmentidos" de "vastíssimos sectores de público leitor, como do MFA e dos centros de decisão político-militares", (2) a "acentuada dificuldade e risco" que os jornalistas encontram quando, no âmbito do seu trabalho, necessitam de contactar a população, "que Ihes não esconde a sua hostilidade" quando identificam o jornal para o qual trabalham, (3) o "evidente sectarismo que resuma da matéria opiniosa inserta do jornal”, um "setor reservado a uma minoria com cujas tomadas de posição não se solidariza grande parte dos redatores, bem como de outros trabalhadores", (4) o "gravoso silêncio com que o Diário de Notícias tem apoiado, implicitamente, o documento «Correia Jesuíno»", que tem a pretensão de "restabelecer a censura à Informação em Portugal”, (5) o “evidente desprezo que as cúpulas da Redação têm manifestado pelo Estatuto Editorial do Diário de Notícias", ao apresentarem notícias sobre política de "teor tendencioso", (6) a "orientação deste jornal que o povo paga do seu bolso" (GOMES, 2014, p. 89-104).

As razões da discordância, assumidas publicamente pelo "grupo dos 30", em relação à "linha orientadora do jornal" e "contra a progressiva marginalização dos seus membros independentes", levaram ainda os jornalistas a justificar o "caráter 
estritamente deontológico da sua atitude" e, por isso, sem ligação a qualquer partido político. Em suma, os 30 jornalistas tinham elaborado um documento que, contendo duras críticas às hierarquias superiores do jornal e ao conteúdo das suas páginas, era, todavia, pouco claro quanto aquele que parecia ser o ponto principal do seu descontentamento: a orientação político-ideológica do periódico. Ficando, assim, por esclarecer no documento que forças políticas estavam a ser privilegiadas no DN, isto é, qual era, efetivamente a sua orientação. Mais tarde, estas e outras dúvidas acabariam por vir a ser dissipadas pelos próprios subscritores.

No que diz respeito à forma como o documento foi divulgado, este foi entregue, em simultâneo, a três órgãos diferentes da Empresa Nacional de Publicidade (ENP): ao Conselho Geral de Trabalhadores (CGT), à administração da ENP e à direção do DN. No entanto, ao mesmo tempo, terá sido divulgado a alguns órgãos de comunicação social (logo no dia seguinte é noticiado pelo semanário Expresso). José Saramago relata da seguinte forma a entrega do documento, feita ao final da tarde de dia 14, à direção do jornal:

O Luís de Barros estava de férias no Algarve, portanto, eu era o responsável pelo jornal e um dia entram três ou quatro jornalistas no meu gabinete com um papel onde manifestavam em nome de 30 jornalistas (os tais que depois se reduziram a 24) a sua discordância com a linha editorial. E pediam, ou melhor, exigiam a publicação no dia seguinte de um comunicado. (...) E eu disse a esses jornalistas que «sim, senhor» mas que havia no jornal uma entidade superior a quem eu teria de submeter a apreciação do documento, que era o Conselho Geral de Trabalhadores. Eles foram-se embora e eu mandei chamar um ou dois dos responsáveis do Conselho Geral dos Trabalhadores e disse-lhes: "Tenho aqui esta coisa. Vocês convoquem para hoje à noite o conselho com as pessoas que estiverem aí, isto é algo de urgente» (SARAMAGO apud SILVA, 2009, p. 54-55).

De acordo com as instruções recebidas de José Saramago, é convocado para essa noite um plenário de urgência, o primeiro de três que viriam a debruçar-se sobre este caso:

Convocado o Conselho Geral de Trabalhadores, à meia-noite, eu subo até ao último andar, onde estava toda a gente reunida, e comunico à assembleia o que se tinha passado, leio o papel dos protestatários e retiro-me para o meu gabinete. E fiquei à espera. Uma hora, duas horas, até que me fossem dizer o que é que tinham decidido. Claro que não deixei de dar a minha opinião sobre aquilo! (SARAMAGO apud SILVA, 2009, p. 55). 
Em declarações ao jornal A Capital, um porta-voz do CGT do DN, não identificado, avança que o plenário contou com mais de 300 trabalhadores - da estereotipia, $2^{\circ}$ e $3^{\circ}$ turnos da tipografia, revisão, redação, gravura, etc. - que rejeitaram, unanimemente, o texto elaborado pelos jornalistas. Os «30» foram ainda descritos como uma "elite" que se colocou sempre à margem da "organização democrática dos trabalhadores do jornal", tendo ultimamente sido "pressionada devido aos ordenados elevados que aufere e aos abusos na marcação de horas extraordinárias", além de incluírem "quatro excolaboradores do CDS [Centro Democrático e Social], um candidato a deputado pelo PPD [Partido Popular Democrático] e outro pela AOC [Aliança Operária Camponesa], quatro colaboradores do jornal Povo Livre, órgão oficial do PPD" e "outros declarados simpatizantes do Partido Socialista" (TRINTA..., 1975, p. 3). O mesmo jornal apresenta ainda declarações do outro "lado" da questão. Um dos signatário do «documento dos 30», também não identificado, defende que o plenário "não representa senão uma tentativa golpista para abafar a tomada de posição destes 30 redatores", tendo como objetivo levar o grupo de jornalistas a repensar a sua posição "através de ameaça de despedimentos e de aposição de conhecidos rótulos políticos". Assim, ao contrário do que se poderia supor, de acordo com este porta-voz dos «30», não foi analisada "nem uma linha do documento", tendo o tempo da reunião sido passado "em insultos aos signatários e em ameaças de saneamentos" (TRINTA... , 1975, p. 3 ).

Nesse mesmo dia, o Diário de Notícias informa os seus leitores da marcação de um plenário para apreciação da atitude dos jornalistas e das sanções a aplicar-lhes, aproveitando para classificá-los de "pequeno grupo de provocadores infiltrados" na empresa e o seu documento de "miserável pasquim" (AVISO..., 1975, p. 1). A polémica sobre a divulgação do documento estava instalada, começando o caso a ter alguma visibilidade na imprensa nacional, correndo rumores de que o texto chegara a ser enviado à $\mathrm{BBC}$ e a outros órgãos de comunicação internacionais.

\section{A polémica decisão de sanear 22 jornalistas}

Fora do jornal, o seu director toma conhecimento, com surpresa, do que se estava a passar através do "aviso dos leitores" publicado no DN. Isto porque, segundo conta, 
quando iniciou as suas férias em finais de julho, nada faria prever os acontecimentos que se sucederam. Percebendo a gravidade da situação, Luís de Barros resolve interromper o seu descanso estival e regressar a Lisboa, chegando a tempo de assistir ao plenário agendado. Entretanto, o grupo de jornalistas realiza uma conferência de imprensa no Teatro Capitólio, em Lisboa, justificando as posições tomadas até então, e a direção do Sindicato dos Jornalistas resolve apoiar, publicamente, os «30», apenas criticando o procedimento por estes adotado, considerando-o "errado: começaram por dirigir-se ao presidente do conselho de Administração (um coronel) e ao subdiretor (responsável, tal como acontece com aquele, pela manipulação verificada), em lugar de terem contactado com a comissão de trabalhadores". É ainda apresentado um protesto contra o facto de o seu presidente, Mário Contumélias, "se encontrar na lista de trabalhadores proposta para «saneamento»" (GOMES, 2014, p. 104-119).

Passados apenas quatro dias da entrega do «documento dos 30», realiza-se mais um longo e agitado plenário de trabalhadores. Na sua longa intervenção, José Saramago é particularmente duro, afirmando, nomeadamente, que o documento "é baseado na mentira, na desonestidade intelectual e política e no impudor mais absoluto em relação ao que seja ou deva ser ou se entenda que possa ser a relação entre pessoas" e dizendo que as atitudes do «grupo dos 30» estão inscritas numa campanha contra o jornal - que já dura há algum tempo. Os 30 jornalistas são ainda acusados de serem “hipócritas e mentirosos", por terem "o inaudito descaramento" de elaborarem um documento contra o jornal enquanto para ele trabalhavam (DOCUMENTOS..., 1975, p. 2). Em plenário, é ainda criticado o facto de estes terem divulgado o documento no exterior do jornal. A direção e vários trabalhadores consideravam que a divulgação do «documento dos 30» noutros órgãos de comunicação social, antes de haver um debate interno, não respeitava o Estatuto Editorial do DN. Um argumento que parecia difícil de rebater, já que o rrt. $^{\circ} 6$ do referido Estatuto era muito claro a esse respeito ${ }^{8}$.

\footnotetext{
${ }^{8}$ O ponto 6 do Estatuto Editorial do DN refere: "O Diário de Notícias adota, no plano orgânico interno, métodos de participação democrática de todos os trabalhadores, tanto no que se refere ao funcionamento das respetivas estruturas técnicas, administrativas e redatoriais, como no que diz respeito às grandes linhas de orientação da informação". Cf. ESTATUTO..., 1975, p. 2.
} 
Esta será, sem dúvida, a principal crítica apontada aos «30» no decorrer dos acontecimentos. Porém, segundo José Jorge Letria, a questão fundamental deste processo não foi "a acusação de que eles tomaram a posição que tomaram", fomentando o "fraccionismo" e sendo "desleais com direção do jornal, a comissão de trabalhadores e com os delegados sindicais", mas sim "a tomada interna do poder". Portanto, na sua opinião, este processo "não tem nada a ver com o jornalismo, tem a ver com a tomada do poder e com o confronto ideológico" (Entrevista cedida por José Jorge Letria ao autor, Lisboa, 2011). Fernando Diogo apresenta outra visão sobre as razões que estão na origem da difusão do documento dos jornalistas: “Foi uma golpada política, mais de quem queria desestabilizar a redação do que propriamente [resolver] os problemas que existissem lá dentro" (Entrevista cedida por Fernando Diogo ao autor, Lisboa, 2012). Duas explicações possíveis de uma atitude sobre a qual pairam muitas dúvidas, subsistindo um intenso debate quanto à existência de uma sintonia de posições no seio do grupo de jornalistas em relação à decisão de divulgar no exterior do jornal o seu documento.

Depois da intervenção de José Saramago, em que analisa criticamente alguns dos pontos do que intitula de "mirabolante papel dos 30", muitos outros dos presentes se manifestaram sobre o tema em debate, entre eles, elementos do "grupo dos 30", jornalistas que não assinaram o documento e trabalhadores da tipografia (GOMES, 2014, p. 119-140). Falou-se em várias medidas a tomar em relação ao caso, mas, após cerca de seis horas de plenário, e já com muitas ausências, foram tomadas as decisões concretas para o futuro dos «30», determinando-se a sua suspensão e o desencadeamento de um processo de inquérito que abriria caminho a propostas de saneamento, sendo essas divulgadas e apreciadas num futuro plenário.

Suspensos os jornalistas, crescia a tensão em torno do seu futuro, a imprensa dava ampla cobertura do acontecimento e, sobretudo, aumentavam as dúvidas quanto às consequências de todo o processo. Em comunicado, os redatores diziam não reconhecer a representatividade de "um plenário que não reuniu mais que uns escassos $25 \%$ dos trabalhadores (menos de 400 em cerca de 1400), sendo as decisões votadas por não mais de centena e meia de participantes." Denunciam ainda o "clima de ódio, de intimidação física, com agressões a trabalhadores e ameaças constantes - até de morte”, acusam 
José Saramago de manipular o plenário "através de uma argumentação na base de subterfúgios oratórios, distorção da verdade, calúnias e insultos aos subscritores do documento" e criticam a forma como se realizaram as votações da proposta final: "foram feitas pelo sistema de braço no ar, que se sabe ser o processo intimidativo usado para manter em silêncio os discordantes" (A RESPOSTA..., 1975, p. 9).

O Sindicato dos Jornalistas mantém o apoio à luta dos redatores e, na Assembleia Constituinte, os deputados José Augusto Seabra (PPD) e Mário Mesquita (PS) também demonstram a sua solidariedade, tendo este último, inclusivamente, apresentado um voto de congratulação pela "corajosa posição crítica" assumida pelos 30 jornalistas e um voto de protesto "contra as ameaças de saneamento e a atitude partidária e anti pluralista da direção" do DN (Diário da Assembleia Constituinte $N^{\circ} 35,1975$ ). Entretanto, alguns jornalistas - seis no total - do «grupo dos 30» desvincularam-se da luta que haviam iniciado há dias. Três deles num espaço de 48 horas após a entrega do documento, em pleno ambiente de efervescência em torno da iniciativa. Segundo Maria Manuela Ferreira, terá sido quebrada a promessa inicial de que o «documento dos 30» teria apenas uma divulgação interna, o que acabou por fazer com que a jornalista percebesse que "havia ali uma manobra político-partidária". Como não concordava com este procedimento, a jornalista reunira-se com o colega João Mendes para discutirem a posição a tomar, acabando os dois por se afastarem do grupo, apesar de não deixarem de concordar com os pontos evocados no «documento dos 30»: "Não desistimos só por desistir. Continuávamos a achar que era preciso mudanças, não estávamos era para entrar em disputas político-partidárias. Queríamos eram soluções profissionais e não soluções políticas" (Entrevista cedida por Maria Manuela Ferreira, Lisboa, 2012).

Efetivamente, ainda que seja praticamente unânime a ideia de que os jornalistas que se desvincularam do grupo não seriam elementos destacados no processo, a verdade é que este desfalque revelava não só a fragilidade do grupo, mas, sobretudo, cedia espaço a críticas que contra ele surgiam, sendo a mais evidente a de que por trás da sua luta estavam interesses político-partidários. 


\section{Do saneamento dos jornalistas ao «caso dos 24»}

A 27 agosto a Comissão de Inquérito nomeada para analisar o polémico caso dos jornalistas apresentou, em plenário de trabalhadores, as suas conclusões. No relatório, publicado nas páginas do jornal, a Comissão diz não fazer distinção entre aqueles que, na fase de inquérito, consideraram incorreta a forma como o grupo organizou a sua luta pois "nem por isso deixaram de atropelar todas as normas por que se regem os trabalhadores desta empresa" - e aqueles que assumem a responsabilidade total dos seus atos. Por isso, opta por deixar à responsabilidade do plenário a decisão quanto ao futuro dos 22 jornalistas (todos exceto os oito que se dessolidarizam do grupo ${ }^{9}$ ) na empresa, isto é, se se mantêm em funções - ainda que possam ser alvo de alguma sanção - ou se são despedidos. Após mais uma acalorada troca de acusações entre os trabalhadores da empresa, a proposta aprovada, com o voto favorável da maioria dos trabalhadores presentes em plenário, estipula o saneamento, sem quaisquer indemnizações, dos 22 jornalistas considerados os principais responsáveis no empolamento exterior do caso. Novamente, a principal crítica feita ao grupo de jornalistas - sendo agora a justificação para o saneamento - foi a de terem divulgado a sua luta fora da empresa.

Apesar de a reportagem do DN referir que os jornalistas subscritores do «documento dos 30" participaram no plenário "livremente, sem quaisquer coações, votando decisões e apresentando propostas", há quem, como Manuela de Azevedo, refira que o plenário correu "muito violentamente" e que, a certa altura, alguém disse que esses jornalistas "precisavam de ir era da janela abaixo" (Entrevista cedida por Manuela de Azevedo ao autor, Lisboa, 2011). Fernando Diogo, que integrara a Comissão de Inquérito, recorda que, durante o plenário, "nenhum deles [«22»] foi impedido de falar em nenhum caso", não deixando, porém, de admitir que o ambiente geral do plenário era “extremamente tenso, com alguma violência verbal, porque algumas pessoas não tiveram grande contenção" (Entrevista cedida por Fernando Diogo ao autor, Lisboa, 2012).

\footnotetext{
9 Trata-se de Álvaro Gomes, Cordeiro Pereira, João Mendes, Jorge Soares, José Sousa Barros, José Valente, Manuel Pereira Rodrigues e Maria Manuela Ferreira.
} 
Note-se que aos 22 jornalistas saneados juntaram-se, por solidariedade, mais dois: João Cordeiro Pereira (que já havia manifestado a sua intenção em plenário) e Jorge Soares. Este último, em carta enviada ao director do DN, revela estranheza por o seu nome constar na lista de redatores que se distanciaram do grupo, manifestando-se “completamente solidário com os seus camaradas afastados" e, por isso, continuando a luta que havia iniciado com os seus colegas (JORNALISTAS..., 1975, p. 3). Estava então criado o "grupo dos 24", gozando o caso de uma forte mediatização, que virá a ser aproveitada pelos próprios e pelos seus apoiantes para difundirem os seus pontos de vista sobre o panorama informativo nacional. O «caso dos 24», como ficou conhecido, originou, nos dias seguintes ao saneamento, novas intervenções na Assembleia Constituinte; múltiplas trocas de comunicados e de acusações entre o Sindicato dos Jornalistas, a administração da empresa proprietária do Diário de Notícias e o próprio grupo de jornalistas; demonstrações de apoio por parte de organizações de jornalistas e de partidos políticos; uma manifestação na Avenida da Liberdade e até uma reunião, entre o Presidente da República e os diretores do DN, onde o caso foi abordado. Pelo meio, foi ainda posto a circular um jornal de luta, elaborado pelos redatores, a que chamaram Notícias dos 24.

Finalmente, refira-se que, analisando a posteriori a decisão de afastar os jornalistas do DN, José Saramago - sem dúvida um dos que maior protagonismo teve neste caso, em contraste, por exemplo, com o próprio diretor do jornal - recusa chamar-lhe um processo de saneamento, mas sim uma decisão de trabalhadores:

Quando se fiz que foi um saneamento, não o foi. Aquilo a que estamos a chamar saneamento - um processo em que pessoas apresentam um papel no qual manifestam o seu desacordo e exigem a uma entidade superior responsável que seja publicado - foi uma decisão, não sei se para bem ou para o mal, do Conselho Geral de Trabalhadores, que decide depois daquilo que o diretor-adjunto foi lá dizer e que, depois de este se ter retirado, promoveu um debate e decidiu pela suspensão e pelo processo disciplinar. É normal. Era absolutamente normal na época... Já me acusaram de tudo, até de ter feito censura, mas eu não o fiz... (SARAMAGO apud SILVA, 2009, p. 56).

Mais uma vez, a ideia de que o diretor-adjunto terá tido o papel principal na decisão de sanear os redatores é negada pelo próprio, permanecendo a dúvida sobre tal facto, sobretudo devido à existência de versões contraditórias. 
Dando ênfase às palavras proferidas por José Saramago em plenário, José David Lopes diz que estas acabaram por ser decisivas para a deliberação final:

Se o Saramago tivesse feito um discurso diferente não tinha havido saneamento, obviamente. O discurso do Saramago, quer no plenário do terceiro turno quer no plenário geral, é que aponta muito o caminho para o afastamento daquela malta. Se o Saramago tivesse feito um discurso, sei lá, mais conciliador... (Entrevista cedida por José David Lopes ao autor, Lisboa, 2011).

No mesmo sentido, José António Santos defende que José Saramago optou por não evitar uma decisão mais radical sobre o processo dos jornalistas:

O Saramago não os empurrou, mas não os segurou e não os segurou porque não quis. Portanto, o Saramago tomou uma posição cómoda para ele. Deitou lume para a fogueira e depois ficou à espera (...). Ele sabia que um gesto dele num sentido ou noutro influenciaria o plenário (Entrevista cedida por José António Santos ao autor, Lisboa, 2012).

Também presente no plenário, Fernando Diogo diz que o diretor-adjunto "teve um discurso vibrante, porque tinha ficado mesmo irritado", mas acrescenta que Saramago "limitou-se a usar aquela capacidade que tinha para persuadir as pessoas de que o ato que aquelas pessoas tinham praticado lhe desagrava e que ele achava que devia ser sancionado", até porque "naquele caso ele teria o plenário já ganho porque a esmagadora maioria das pessoas estaria obviamente com ele" (Entrevista cedida por Fernando Diogo ao autor, Lisboa, 2012). De qualquer forma, algo parece inequívoco: o saneamento dos redatores foi uma decisão tomada pela maioria dos trabalhadores presentes em reunião plenária (muito criticada, nomeadamente quanto à sua representatividade, votação de braço no ar, etc.), o que não afasta a ideia de que terá havido uma união de trabalhadores próximos do PCP no sentido de expulsar os jornalistas. Afasta, sim, a tese de que existe um único responsável pelo saneamento dos jornalistas, embora seja inegável que houve, efetivamente, figuras com maior interferência no processo. 


\section{O 25 de Novembro e a nova atitude face aos «24»}

Na sequência da tentativa de golpe de 25 de Novembro é declarado, nesse mesmo dia, o estado de sítio na área da Região Militar de Lisboa. Os jornais de Lisboa, entre os quais o DN, deixaram de se publicar, reaparecendo aos poucos durante o mês de dezembro.

No dia 27 de novembro, o Conselho da Revolução faz um breve balanço da atividade da imprensa estatizada, salientado que o seu "défice global mensal é da ordem dos 50 mil contos" e que "alguns destes jornais têm produzido informação tendenciosa, distorcida e monolítica" (SUSPENSA..., 1975, p. 1). Neste sentido, o CR toma uma série de medidas, entre elas a demissão imediata de todos os membros em exercício da administração empresas de media estatizadas e a dissolução de todos os órgãos ou corpos sociais das mesmas empresas, com destituição dos respetivos membros em exercício (DIÁRIO DO GOVERNO, 1975) ${ }^{10}$. No DN, a nova administração é designada logo a 5 de dezembro pelo Conselho de Ministros, passando a ser composta pelo Coronel Mário de Carvalho Andrea, Francisco Lyon de Castro e Fernando Oneto.

A 16 de dezembro é difundida a notícia de que 14 trabalhadores do DN teriam sido suspensos e proibidos de entrar nas instalações do jornal sem autorização prévia da nova administração. Entre eles encontravam-se os diretores, Luís de Barros e José Saramago, e o repórter Mário Ventura Henriques, que viriam a ser alvo de um inquérito ${ }^{11}$. Nos dias seguintes, como seria de esperar, surgem na imprensa várias reações dos elementos suspensos, notando-se uma inversão de papéis. Se anteriormente os termos utilizados para classificar os saneamentos ocorridos em agosto eram em muito semelhantes aos que são utilizados agora, os protagonistas mudaram.

Entretanto, alguns dos jornalistas do DN agora suspensos - José Jorge Letria, Leonor Martinho Simões, Rogério Carapinha, Daniel Ricardo, João Paulo Velez e David Lopes Ramos - começam a apresentar as suas demissões, aceites pela administração do

\footnotetext{
11 Da lista dos suspensos, embora não desempregados, fizeram ainda parte: Daniel Ricardo, Figueiredo Filipe, José David Lopes, José Jorge Letria, Mário Rosendo, Rogério Carapinha, Leonor Martinho Simões, João Paulo Velês, José Luiz Jacinto Fernandes, David Lopes Ramos e Ernesto Sampaio.
} 
jornal $^{12}$. Ainda em dezembro, grande parte do "grupo dos 24» integra a fundação do jornal O Dia, sob direção de Vitorino Nemésio. Paralelamente, começam a circular rumores de que estaria a ser preparado o lançamento de um novo jornal diário, de tendência comunista, que iria integrar alguns dos jornalistas suspensos de vários órgãos de comunicação. O Diário, como se chamará, chega às bancas em janeiro de 1976 integrando alguns jornalistas que haviam sido suspensos do DN e tendo como diretor Miguel Urbano Rodrigues. Curiosamente, José Saramago ficou de fora do novo jornal'13, tendo sido, segundo Carlos Brito, vetado pelo próprio Secretário-geral do PCP: “em certos meios político-militares as posições do jornal [Diário de Notícias] eram vistas como inspiradas pelo Partido, o que irritava Cunhal que se tornou muito crítico em relação aos camaradas que o dirigiam, em especial em relação a Saramago” (BRITO, 2010, p. 339).

O Diário de Notícias, agora sob a direção de Vítor Cunha Rêgo e Mário Mesquita (dois conhecidos militantes e fundadores do PS), voltaria às bancas a 22 de dezembro, quase um mês depois da sua última publicação. O primeiro texto da nova direção, publicado na primeira página com o título “Um jornal do Estado e do Povo", traçava as principais linhas orientadoras para o futuro do matutino, tentando descolá-lo da imagem, muito criticada nos últimos meses, de que não respeitava posições ideológicas diferentes das da sua direção:

Este jornal pertence ao Estado Português. Não pode ser feudo de nenhum grupo social, nem de qualquer organização política. Na sua prática diária, há-de reger-se pelos grandes princípios já definidos, na Assembleia Constituinte, para a Imprensa Estatizada: pluralismo de opiniões e independência perante o Governo e a Administração Pública. (...) Pluralismo que entendemos, não como somatório de elucubrações ideológicas ou amontoado de propagandas sectoriais, mas como possibilidade de expressão e confronto das correntes políticas representativas. (...) (UM JORNAL..., 1975, p. 1).

\footnotetext{
${ }_{12}$ Daniel Ricardo e Rogério Carapinha terão apresentado a sua demissão em 15/12/1975 e os restantes em 31/12/1975. Luís de Barros só apresentará a sua demissão a 10/1/1976.(Ordem de Serviço Nº 2/76, 1976).

${ }^{13}$ É o próprio José Saramago que refere ter tomado conhecimento da preparação deste matutino por elementos próximos do PCP logo em Novembro, oferecendo-se para nele colaborar. Porém, nunca terá sido chamado. O motivo, segundo conta, prende-se com o facto de ter deixado de frequentar as reuniões do seu partido quando tomara posse no Diário de Notícias: "Não perdoaram que eu tivesse aparentemente renunciado às minhas obrigações - simplesmente eu tinha outras! - além de ir à célula receber instruções"( SILVA, 2009, p. 127.).
} 
Tornava-se, assim, clara a postura da nova direção do DN, sendo que o texto por ela assinado podia ser entendido não apenas como dirigido aos seus leitores, mas também, dados os recentes acontecimentos, aos próprios trabalhadores do jornal.

Já o mês de janeiro ia praticamente a meio quando o Conselho de Imprensa (Cl), órgão pioneiro na regulação dos media em Portugal, apresenta as conclusões a que chegara a propósito da queixa apresentada pelos «24» jornalistas do Diário de Notícias. Após ter analisado o processo, o Conselho resume o motivo que originou o saneamento dos redatores ao facto de os mesmos contestarem a orientação ideológica do jornal. Por isso, para formular uma deliberação final, o $\mathrm{Cl}$ tentou verificar se houve ou não uma alteração na orientação ideológica do jornal e, consequentemente, se terá a direção violado o seu Estatuto Editorial, concluindo:

$\mathrm{Na}$ verdade, se apenas o que esteve em causa foi a crítica feita à orientação ideológica do jornal não se pode ter como legítima a atitude assumida, quando é certa que da análise dos vários exemplares do jornal resulta que deixou de se observar aquela informação apartidária e independente que devia ter. Por outro lado, vê-se que trabalhando na empresa proprietária do jornal para mais de mil trabalhadores, 0 afastamento dos 24 jornalistas se fez por um processo de "saneamento" - maneira de proceder, aliás muito discutível - num plenário escassamente representativo (ANEXO..., 1976).

Tendo como base esta lógica de ideias, o Conselho de Imprensa acaba por considerar "ilegal e ilegítimo o fundamento invocado para o afastamento dos jornalistas", considerando-o até "atentatório da liberdade de expressão do pensamento salvaguardada na Lei de Imprensa" (ANEXO..., 1976). Finalmente, cerca de um mês depois, a ENP, através do administrador Mário de Carvalho Andrea, refere-se ao caso, esclarecendo que apenas considera terem sido saneados 22 dos 24 jornalistas mencionados pelo Conselho, pois "dois deles [Jorge Soares e Cordeiro Pereira] decidiram solidarizar-se com os restantes 22 deixando de comparecer ao serviço". O administrador diz ainda que já haviam sido "contactados os 22 jornalistas e mais outros 7 que se encontravam em situação análoga, estando agora a ser decidida a forma para a resolução do problema" e que o inquérito aberto pela ENP tinha concluído que os jornalistas foram “ilegalmente afastados” (CARTA..., 1976). 
As novas posições por parte dos administradores da ENP acabariam por chegar e o final de maio traz consigo novidades para os dois grupos de jornalistas afastados do Diário de Notícias. Aos suspensos após o 25 de Novembro foi dada como terminada a situação de suspensão, com a finalidade de lhes serem agora instaurados processos disciplinares ${ }^{14}$. No que diz respeito aos 22 saneados em agosto do ano anterior e a mais alguns jornalistas afastados antes do 25 de Novembro, a administração da ENP considerou que os seus saneamentos ocorreram "por processos não ortodoxos, sem a tramitação e invocação de lei vigente". Por isso, resolvera considerar "sem nenhum efeito" o seu afastamento. Ficou ainda acordado que seriam instaurados "processos disciplinares aos elementos que tenham feito parte de comissões de inquérito ou de saneamento ou elaborado de má fé propostas cuja aprovação tenha causado lesão nos direitos de outros trabalhadores e prejuízos à empresa" (ORDEM DE SERVIÇO N², 1976).

Depois de ser tornada pública a posição da administração da ENP sobre o «caso dos 24" é dada a possibilidade aos jornalistas de regressarem ao jornal ou, caso preferissem, serem indemnizados. Muito embora o processo de reintegração dos jornalistas no DN não tenha sido propriamente pacífico, com alguns trabalhadores a oporem-se terminantemente a esta decisão, alguns foram voltando e integraram-se na redação. É o caso de Manuela de Azevedo, Luís d’Oliveira Nunes e José Simões Ilharco, que regressam logo em julho. Como a deliberação da ENP deixava em aberto a possibilidade dos jornalistas regressarem quando assim o entendessem, mais tarde, são readmitidos também Alda Mafra, Acácio Franco e José Estêvão Santos Jorge.

Outros jornalistas, como Francisco Máximo e Mário Contumélias, revelam ter-lhes sido aconselhado a seguir um caminho distinto. O primeiro conta que lhe foi oferecido, na altura que se deslocou ao DN, o cargo de Assessor de Imprensa na Embaixada Portuguesa da Áustria como forma de o demover da ideia de voltar à redação do DN, visto que o seu regresso poderia originar conflitos com alguns dos trabalhadores do jornal (Entrevista cedida por Francisco Máximo ao autor, Lisboa, 2011). A Mário Contumélias aconteceu uma

\footnotetext{
${ }^{14}$ Trata-se de Mário Ventura Henriques, Alfredo Figueiredo Filipe, José David Lopes, Mário Rosendo, José Luíz Fernandes e Ernesto Sampaio. Note-se que estes jornalistas, apesar de suspensos, continuavam a receber os seus salários enquanto funcionários do DN. Alguns deles viriam, durante o período de suspensão, a colaborar noutros jornais.
} 
situação semelhante, pois, segundo conta, um administrador da ENP ter-lhe-á dito: "Se tu quiseres podes voltar, já houve quem voltasse, portanto também podes voltar, mas eu gostava que tu não voltasses, porque, se tu voltas, a Tipografia tem-te um ódio de morte... se tu voltas para aqui não há paz cá dentro". Perante esta posição, o jornalista terá optado por não regressar e apenas receber a indemnização que havia sido acordada (Entrevista cedida por Mário Contumélias ao autor, Lisboa, 2011).

Embora faltasse resolver a situação de seis redatores suspensos após o 25 de Novembro, um processo que se prolongará para depois do verão de 1976 aparentemente o «caso dos 24» havia chegado ao fim cerca de um ano após o seu início. O confronto travado em torno deste caso - amplamente explorado pela imprensa - ficava para trás, tal como o processo revolucionário.

\section{Considerações finais}

Apesar de sabermos que os processos de saneamento foram diversificados, variando consoante as áreas e motivações dos seus protagonistas, decorrendo frequentemente fora do domínio das autoridades político-militares, e que o caso por nós estudado não se enquadra na vaga de saneamentos, alicerçados em legislação, que atingiu os vários sectores da sociedade portuguesa logo após o 25 de Abril de 1974 - os chamados «saneamentos legais», que se destinavam a indivíduos com ligação ao anterior regime - estamos perante um episódio que revela, desde logo, o elevado grau de conflitualidade que existiu entre correntes político-ideológicas distintas, ao longo do período revolucionário. Depois, mostra também a relevância dos plenários de trabalhadores neste contexto, assim como a capacidade de mobilização dos trabalhadores do setor da informação na defesa das suas posições. Sendo este um processo conduzido por trabalhadores, sem suporte legal, os motivos estritamente político-ideológicos como justificação para o afastamento dos jornalistas ganham fundamento, enquadrando-se o caso nos chamados «saneamentos selvagens», muito

\footnotetext{
${ }^{15}$ Mário Ventura Henriques, José David Lopes, Ernesto Sampaio, Mário Rosendo e Alfredo Figueiredo Filipes, após processos disciplinares, contestações aos processos (que acabariam por prescrever) e várias solicitações para regressarem ao jornal, veriam, por ordem do Conselho de Gerência, levantada a sua suspensão, em Outubro de 1978, voltando, assim, à redação do DN.
} 
embora - como acontece ainda, por exemplo, relativamente ao caso República - falte esclarecer a grande incógnita que acompanhou todo este processo e que tem permanecido sem resposta até à atualidade, mantendo os protagonistas posições distintas sobre o assunto: na origem deste processo esteve sobretudo um descontentamento de nível laboral, adquirindo posteriormente uma dimensão política, ou desde o princípio este foi um caso muito mais político do que do foro laboral ou jornalístico?

\section{Referências}

ANEXO ao Comunicado do Conselho de Imprensa de 12/1/1976. Lisboa, 1976. Fundo Conselho de Imprensa. Arquivo Nacional Torre do Tombo.

A RESPOSTA dos trinta ao plenário. Jornal Novo, Lisboa, 20 de Agosto de 1975, p. 9.

AVISO aos leitores do "Diário de Notícias". Diário de Notícias, Lisboa, 15 de Agosto de 1975, p. 1.

AZEVEDO, Manuela de. Entrevista cedida a GOMES, Pedro Marques. Lisboa, 2011. Informação oral.

BARROS, Luís. Entrevista cedida a GOMES, Pedro Marques. Lisboa, 2011. Informação oral. BORRAT, Héctor. El periódico, actor del sistema político. Anàlisi: quadernos de comunicació i cultura. Barcelona: UAB, 1989. p. 67-80

BRITO, Carlos. Álvaro Cunhal: sete fôlegos de um combatente. Lisboa: Edições Nelson de Matos, 2010.

CANDEIAS, João. Entrevista cedida a GOMES, Pedro Marques. Lisboa, 2012. Informação oral.

CARTA enviada ao Conselho de Imprensa, 17/5/1976. Lisboa, 1976. Fundo Conselho de Imprensa. Arquivo Nacional Torre do Tombo.

COMUNICADO Nº 1 - Comissão de Saneamento da ENP. Lisboa: Empresa Nacional de Publicidade, 19 de março de 1975. 
CONTUMÉLIAS, Mário. Entrevista cedida a GOMES, Pedro Marques. Lisboa, 2011. Informação oral.

DIÁRIO DA ASSEMBLEIA CONSTITUINTE N 35. Parlamento, Lisboa, 22 de Agosto de 1975. DIÁRIO DO GOVERNO, I Série, n²75, Lisboa, 1975.

DIOGO, Fernando. Entrevista cedida a GOMES, Pedro Marques. Lisboa, 2012. Informação oral.

DOCUMENTOS e decisões do plenário de trabalhadores do "DN". Diário de Notícias, Lisboa, 19 de Agosto de 1975, p. 2.

ESTATUTO Editorial do Diário de Notícias. Diário de Notícias, Lisboa, 26 de Junho de 1975, p. 2.

FERREIRA, Maria Manuela. Entrevista cedida a GOMES, Pedro Marques. Lisboa, 2012. Informação oral.

FIGUEIRA, João. Os jornais como actores políticos: O Diário de Notícias, Expresso e Jornal Novo no Verão Quente de 1975. Coimbra: MinervaCoimbra, 2007.

FILIPE, Figueiredo. Entrevista cedida a GOMES, Pedro Marques. Lisboa, 2012. Informação oral.

FLASHES do Diário de Saramago. O Diabo. Lisboa, 9 de Junho de 1992, p. 12.

GOMES, Pedro Marques. Os saneamentos políticos no Diário de Notícias no verão quente de 1975. Lisboa: Alêtheia Editores, 2014.

GOMES, Pedro Marques. Jornais, jornalistas e poder: a imprensa que nasce na revolução e as lutas políticas de 1975. 2018. Tese (Doutorado em História Contemporânea) - FCSHNOVA, Lisboa, 2018.

JORNALISTAS despedidos do "Diário de Notícias" determinados a lutar contra “manipulação da informação”. A Capital, Lisboa, 30 de Agosto de 1975, p. 3.

LETRIA, José Jorge. Entrevista cedida a GOMES, Pedro Marques. Lisboa, 2011. Informação oral.

LIMA, Helena. Os diários portuenses e os desafios da actualidade na imprensa: tradição e rupturas. 2008. Tese (Doutorado em História) - FLUP, Porto, 2008.

LOFF, Manuel. Estado, democracia e memória: políticas públicas da memória da ditadura portuguesa (1974-2014). In: LOFF, Manuel; SOUTELO, Luciano; PIEDADE, Filipe (Coord.). 
Ditaduras e revolução: democracia e políticas da memória. Coimbra: Almedina, 2016, p. 23-143.

LOPES, José David. Entrevista cedida a GOMES, Pedro Marques. Lisboa, 2011. Informação oral.

MÁXIMO, Francisco. Entrevista cedida a GOMES, Pedro Marques. Lisboa, 2011. Informação oral.

MESQUITA, Mário. O caso República ou o símbolo destruído. Cadernos de Imprensa. Lisboa: Clube Português de Imprensa, 1987.

MESQUITA, Mário. Os meios de comunicação Social. In: REIS, António (Dir.). Portugal 20 anos de democracia. Lisboa: Círculo de Leitores, 1994, p. 361-405.

NÃO DOU a face direita a quem me atinge a esquerda. O Dia, Lisboa, 14 de Agosto de 1976, p. 2.

NUNES, Luís d'Oliveira. Entrevista cedida a GOMES, Pedro Marques. Lisboa, 2012. Informação oral.

O DIRECTOR que marcou o «Verão quente» de 1975. Diário de Notícias, Lisboa, 2010. Disponível em: https://www.dn.pt/portugal/interior/o--director--que-marcou-o-veraoquente-de-1975-1597476.html. Acesso em 20 de Março de 2011.

O DN vai ser um instrumento para a construção do socialismo. Diário de Notícias, Lisboa, 10 de Abril de 1975, p. 1-2.

ORDEM DE SERVIÇO N², Lisboa, Empresa Nacional de Publicidade, 1976.

PIMENTEL, Irene Flunser. O caso da PIDE/DGS. Lisboa: Temas e Debates, 2017.

PINTO, António Costa. Enfrentando o legado autoritário na transição para a democracia 1974-1976. In: BRITO, J. M. Brandão de (Dir.). O país em revolução. Lisboa: Editorial Notícias, 2001. p. 359-384.

PINTO, António Costa. O legado do autoritarismo e a transição para a democracia, 19742004. In: MEIRELES, Maria Conceição; LOFF, Manuel (Coord.). Portugal: 30 anos de democracia (1974-2004). Porto: Editora da Universidade do Porto, 2006.

PIRES, Fernando. Os meus 50 anos no Diário de Notícias. Lisboa: JM Edições, 2012.

REBELO, José. República. Caso do jornal. In: REIS, António, REZOLA, M. Inácia; SANTOS, Paula B. (Coord.). Dicionário de história de Portugal: o 25 de abril. v. 7. Porto:

Figueirinhas, 2018. p. 169-173. 
REIS, António. A revolução de 25 de abril de 1974, o MFA e o processo de democratização. In: REIS, António (dir.). Portugal Contemporâneo. v. 6. Lisboa: Publicações Alfa, 1993, p. $13-62$.

RELATÓRIO DO CONSELHO DE IMPRENSA. A Imprensa escrita em Portugal (abril de 1974 a julho de 1975). Lisboa: Conselho de Imprensa , 1979.

REZOLA, Maria Inácia. Os militares na revolução de abril: o conselho da revolução e a transição para a democracia em Portugal. Lisboa: Campo da Comunicação, 2006.

REZOLA, Maria Inácia. Justiça e Transição: os juízes dos tribunais plenários. In: REZOLA, Maria Inácia; PIMENTEL; Irene Flunser (Coord.). Democracia e ditadura: memória e justiça política. Lisboa: Tinta-da-China, 2013. p. 177-178.

RIBEIRO, Nelson. A rádio renascença e o 25 de Abril. Lisboa: Universidade Católica Portuguesa, 2002.

SANTOS, José António. Entrevista cedida a GOMES, Pedro Marques. Lisboa, 2012. Informação oral.

SANTOS, Paula Borges, Igreja católica, estado e sociedade 1968-1975: o caso Rádio Renascença. Lisboa: Imprensa de Ciências Sociais, 2005.

SARAMAGO, José. Os Apontamentos. Lisboa: Caminho, 1990.

SEABRA, Zita. Foi assim. Lisboa: Alêtheia Editores, 2007.

SEATON, Jean; PIMLOTT, Ben. The Portuguese media in transition. In: MAXWELL; Kenneth (dir.). The press and the rebirth of iberian democracy. Connecticut: Greenwood Press, 1983, p. 93-115.

SILVA, João Céu E. Uma longa viagem com José Saramago. Lisboa: Porto Editora, 2009.

SILVEIRA, Joel da. A construção do sistema informativo em Portugal no Séc. XX. Lisboa: Colibri, 2011.

SUSPENSA a publicação dos jornais estatizados. O Primeiro de Janeiro, Porto, 29 de Novembro de 1975, p. 1 e 9.

TELO, António J. História contemporânea de Portugal: do 25 de abril à atualidade. v. I. Lisboa: Editorial Presença, 2007.

TOVAR, Rui. Entrevista cedida a GOMES, Pedro Marques. Lisboa, 2011. Informação oral. 
TRINTA jornalistas do "Diário de Notícias" denunciam sectarismo informativo. A Capital, Lisboa, 16 de Agosto de 1975, p. 3.

UM JORNAL do Estado e do Povo. Diário de Notícias, Lisboa, 22 de Dezembro de 1975. 